Research Article

\title{
Aerodynamic Forces Affecting the H-Rotor Darrieus Wind Turbine
}

\author{
Faris Alqurashi $\mathbb{D}^{1,2}$ and M. H. Mohamed ${ }^{2,3}$ \\ ${ }^{1}$ Mechanical Engineering Department, College of Engineering, University of Bisha, Bisha 61922, Saudi Arabia \\ ${ }^{2}$ Mechanical Engineering Department, College of Engineering and Islamic Architecture, Umm Al-Qura University, P.O. 5555, \\ Makkah, Saudi Arabia \\ ${ }^{3}$ Mechanical Power Engineering Department, Faculty of Engineering-Mattaria, Helwan University, P.O. 11718, Cairo, Egypt
}

Correspondence should be addressed to Faris Alqurashi; fars421@hotmail.com

Received 15 April 2019; Revised 9 September 2019; Accepted 3 December 2019; Published 11 January 2020

Academic Editor: Michele Calì

Copyright (c) 2020 Faris Alqurashi and M. H. Mohamed. This is an open access article distributed under the Creative Commons Attribution License, which permits unrestricted use, distribution, and reproduction in any medium, provided the original work is properly cited.

\begin{abstract}
Darrieus wind rotor is a vertical axis wind turbine that is a very promising kind of wind converters at remote and domestic locations that have soft and weak wind potential and speed, but from the quantitative comparison with horizontal axis wind turbines, this type of turbines has a weak performance. Additional researches are still needed to develop its efficiency to identify all the requirements of the generated power in low power demands. The aim of the current investigation is to analyze all the acting forces on the main parts of Darrieus rotor over the rotations as well as in maintenance and stationary conditions. Aerodynamic forces assessment will be executed for 3 different blade shapes (nonsymmetric and symmetric airfoils) like the airfoil section shapes of the Darrieus rotor blades. NACA 0021, LS413, and S1046 are selected as cross-sectional profile in this work. CFD simulations have been used in this work to get the different aerodynamic forces on the rotor blades of the Darrieus turbines. The present results indicated that the symmetric S1046 blade has higher forces during the rotation and stagnant (static) conditions. Moreover, the self-starting capability of NACA 0021 is better than S1046 due to low aerodynamic torsion on the S1046 blades.
\end{abstract}

\section{Introduction}

Recently, wind energy is a considerable and significant source of power in the world. Wind power must be classified as one of the significant growths in the $20^{\text {th }}$ century. Few years ago, steam power stations played a large role in the technology of power generation, and the fossil fuels would seem to have forever relegated to insignificance the role of the wind in energy generation. Nowadays, wind energy is a considerable source of electricity in a lot of countries. Power fields which used wind energy are installed with high capacities in most countries of the world. Converting the kinetic energy has been introduced by many devices, which contained movable parts in the direction of wind stream to convert it into mechanical work and then to electricity by the generators. Aerodynamic characteristics are the main base in the wind turbines classifications. The aerodynamic force acting on an airfoil is conventionally resolved into its components parallel (drag) and normal (lift) to the freestream velocity vector. Therefore, the aerodynamic analysis of the turbine is characterized by the following: (a) the wind turbine that holds and seizes its mechanical energy from the aerodynamic drag force of the wind flow is called drag wind turbine; (b) the wind turbine that deals with the aerodynamic lift force over the blades airfoils is called lift wind turbine. By this classification and analysis, both of these turbines are designed as vertical axis wind turbines. In addition, the aerodynamic parameter called "tip-speed ratio" is used to describe the wind turbines performance. It is divided into "low speed turbines" and "high speed turbines." Wind turbines classification is divided depending on the positions and locations of the turbine axis of rotations. Therefore, it would be assorted into vertical axis wind turbine (VAWT) rotating around this normal axis. In 
addition, other patterns rotate about a horizontal axis. Therefore, they are called horizontal axis wind turbines and these types are known to the public due to the commercial pervasion.

Recently, effective and efficient VAWTs were improved and upgraded to be considerable wind converter. Darrieus rotors were invented in the $3^{\text {rd }}$ decade of the twentieth century in France. Regularly, Darrieus rotors consist of 2 or 3 blades but these blades are positioned parallel to the rotor axis. The vertical axis wind turbines (VAWTs) have characteristics of simplicity, easy design, mechanical housing, no yaw systems, gearboxes, and generators, and mechanical and electrical elements are easily reached on ground level. Therefore, they are characterized by convenient installations and suitable maintenance. Meanwhile, there are various disadvantages facing this wind rotor like low efficiency, disability and insufficiency to self-starting, and no ability to control the rotor power output. Therefore, the turbines control speed by using variable pitch angles like other forms of blades. Darrieus rotors (with H-shaped blade) are structured instead of conventional curved blades called egg-shaped blades. As represented in Figure 1, the designer linked the $\mathrm{H}$-rotor blade to the rotating axis by struts [1].

After this display and definition, it is obvious that Darrieus turbines have a numerous potential for amplifications that were not gained so far. Extra money, additional efforts, and further time are needed to fulfill optimum design for this turbine.

\section{State of the Art and Previous Work Gaps}

Recently, a lot of interesting attempts and research papers in different countries were achieved in the scope area of wind turbine to solve the energy problems and crisis in those countries. In the last twenty years, the horizontal axis wind turbine received much attention in the development to increase its performance. Meanwhile, there is no fine, good, and valuable interest for vertical axis wind turbines that operate in the urban zones under low wind speed.

Vertical axis wind turbine (VAWT) such as Darrieus turbine is particularly important and interesting for urban zones, but it has some drawbacks such as low efficiency and weak power output; if it was compared with horizontal axis wind turbine, bad self-starting capability is a main disadvantage in VAWT.

Straight blades Darrieus wind turbine which is an appropriate alternative and is obtained from the standard shape has even more engaging characteristics as easy manufacturing, installation, and construction. Therefore, the Darrieus turbine that has straight blades is called $\mathrm{H}$-rotor Darrieus turbine. The $\mathrm{H}$-rotor system has straight and vertical blades instead of standard shapes that have curved blades of the Darrieus turbine. Directly, horizontal struts connect the blades and shaft. The position of these struts is sometimes on the ends or the middle of the blades as shown in Figure 1. One of the major and essential characteristics of the vertical axis wind turbine is the ability to collect wind from different directions. Moreover, straightforward and simple design and manufacturing lead to easy build as well as

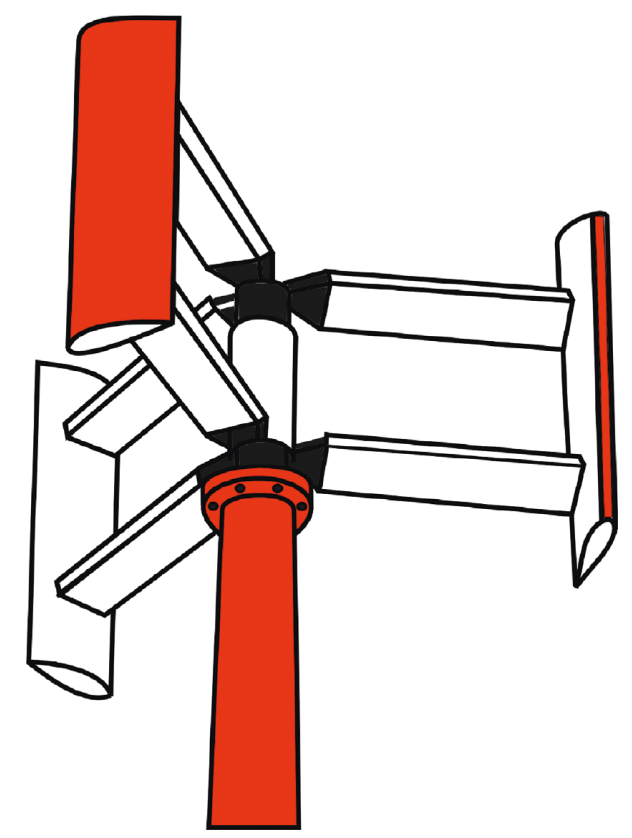

FIgURE 1: Straight rotor of Darrieus wind turbine.

easy installation and maintenance. These features lead to considerably lower costs with comparison to other types of wind turbines. Aerodynamic simulation of this turbine is very difficult quantitatively and quantitatively due to separation and dynamic stall of the flow around the blades. Optimum design has not been gained yet even if a lot of considerable and significant published researches have already been introduced for this configuration.

Through calculation methods and experiments, many publications have attempted to recognize the major appropriate concepts of operation and to enhance the performance distinctive of the Darrieus rotor. Takahashi et al. [2] tried experimentally and numerically to improve the output power of the straight wing vertical axis wind turbines (SWVAWTs) by investigating several sectional profiles. The double multiple stream tube model under transient conditions (analytical solution) is performed as a solution method. That method was utilized to deduce the aerodynamic results by Mukinovic et al. [3] for the performance of Darrieus rotors. Kumar et al. [4] offered an appropriate system of Darrieus (H-rotor) turbines using both BEM and CFD methods.

A CFD model was introduced by Castelli et al. [5] to evaluate and assess the performance of a Darrieus wind rotor under several conditions. That simulation used a sectional profile of NACA 0021 airfoil and the two-dimensional campaign to study the turbine's performance. In order to estimate the aerodynamic efficiency of the H-rotor Darrieus wind turbines, Sabaeifard et al. [6] deduced some results that have investigated experimentally and computationally. Various designs and aerodynamic parameters like sectional profiles, number of blades, and solidities are investigated in that paper. The optimum design was gained with an optimal power output coefficient of 0.36 .

By testing 20 nonsymmetric and symmetric airfoils, Mohamed [7] increased performance of Darrieus turbine. 
He summarized that S1046 sectional profile is the optimal airfoil to construct Darrieus turbines with higher performance than the other sectional profiles in the current study. By CFD methodology, El-Baz et al. [8] improved the aerodynamic power coefficient of the Darrieus H-rotors. This group deduced an optimal configuration with 15\% higher power coefficient than the conventional turbines.

Mohamed evolved in [9] the self-starting capability by using different methods to fix the problem of the turbines' self-starting, which is the essential disadvantage of the Darrieus rotors. Numerically, the section profiles with several airfoils were studied by Kanyako and Janajreh [10] with the CFD techniques. Kanyako and Janajreh tested some airfoils such as S1046, NACA 0015, NACA 0018, and DU06-W-200. They deduced that NACA 0015 has an optimum power coefficient within low tip-speed range. The effect of the Courant-Friedrichs-Lewy (CFL) criterion has been discussed by Trivellato and Castelli [11] and they studied the effect of the angular marching time step on the numerical simulation results on the accuracy of the Darrieus turbine. The sectional profile and the pitch angle have been examined by Mohamed et al. [12]. They studied 25 different profiles of nonsymmetric and symmetric airfoils using the numerical CFD simulations. The authors concluded that LS 413 (nonsymmetric) and S1046 (symmetric) were the best airfoils to obtain optimum performance. Bianchini et al. [13] presented the influence of the chord length on the turbine radius ratio parameter in the tiny turbine utilizing CFD simulations for three-sectional airfoil shapes in the Darrieus rotor motions. Watanabe et al. [14] clarified a main impact of the wind accelerations arrangement by calculating the power coefficient like "wind-lens" design.

Wind-lens design factors like semiopen angles, diffuser lengths, and wind-lens locations have been studied as well as the different section profile shapes. These researchers concluded and deduced that the profile of NACA 0024 is the optimum and convenient type for Darrieus turbines using a wind lens.

Aerodynamically, most of the above publications have attempted to raise and boost the efficiency and self-start of Darrieus turbine. Almost all of the experimental and theoretical publications mentioned above in this section are only interesting for using traditional symmetric NACA 00XX sectional profiles. Despite that, there is no argument or evidence that NACA sectional profiles are the optimum profile shapes for these types of VAWTs (H-rotor Darrieus turbines). In addition, none of these papers studied the different forces around the blades and whether these blades consist of symmetric or nonsymmetric airfoils. Therefore, in the preset work, the authors investigated the static and the dynamic forces around the blades with different sectional profiles such as NACA 0021, LS413, and S1046 to help the designers and the manufacturers to select and design the different mechanical parts of the Darrieus turbine.

\section{Operation Principles}

During the air flow of the wind across the turbine and its blades through the sectional profiles of $\mathrm{H}$-rotor, the blade generates beneficial torque and power. Like all rotating blades in the turbomachinery, velocity triangles will be produced on all points of the blades. These triangles consist of the relative velocity $W$ that has been created between the flow velocity, $V_{a}$, and the peripheral blade speed, $u$, as represented in Figure 2. There is another significant parameter that can be defined as speed ratio, $\lambda$. Speed ratio is a ratio between the blade peripheral speed $\omega R$ and the free stream wind velocity $U_{\infty}$, and this ratio is defined as

$$
\lambda=\frac{\omega R}{U_{\infty}} .
$$

A straightforward relation is governing the angle of attack $\alpha$ with the azimuth angle $\theta$ and the speed ratio $\lambda$. It can be calculated by (2). That equation will be deduced from the analysis of velocity triangles (as shown in Figure 3) as follows:

$$
\alpha=\tan ^{-1}\left[\frac{\sin \theta}{\lambda+\cos \theta}\right]
$$

where

$$
w=\sqrt{V_{c}^{2}+V_{n}^{2}}
$$

where $V_{c}$ is the velocity (chord base) and $V_{n}$ are the normal velocity components.

Different aerodynamic forces can be generated on the sectional profile of the blades due to air flow stream through the turbine rotors. Mainly, those forces were called drag and lift forces: the drag force $F_{D}$ in the direction of the air flow and the lift force $F_{L}$ perpendicular to the air flow. Aerodynamically, these forces have deep relations with the angle of attack $\alpha$ of the wind. Occasionally, these angles in irregular conditions or in pitching cases are called incidence angles. With solving those forces, normal forces $F_{N}$ and the tangential forces $F_{T}$ are accountable forces of the torque and power outputs are gained as shown in Figure 2 .

The function between the attack angles, azimuth angles, and the speed ratio was formulated by (2). Figure 3 presents a distinction and singularity of the attack angles as a result of a variation of the azimuth angles and the speed ratios through all revolutions of the rotations of the H-rotor.

The figure indicates also that, within higher speed ratios $\lambda$, the attack angle range variations become lower. This impact is very substantial and it can be considered in the simulation of Darrieus turbines.

Another major parameter that influences the forces on the sectional profile is the rotor solidity. The solidity is the essential factor to determine shape dimensions of the Darrieus turbines; it can be defined as

$$
\sigma=\frac{N c}{2 R},
$$

where $N$ is the number of blades, $c$ is length of chord of any airfoil, and $R$ is turbine's radius.

Several forces and performances of Darrieus H-rotor turbines depend on various factors such as the free stream wind velocity, $U_{\infty}$, output of power, $P$, aerodynamic positive torque, $T$, on the axis of rotation, and effective rotor area, $A$. 


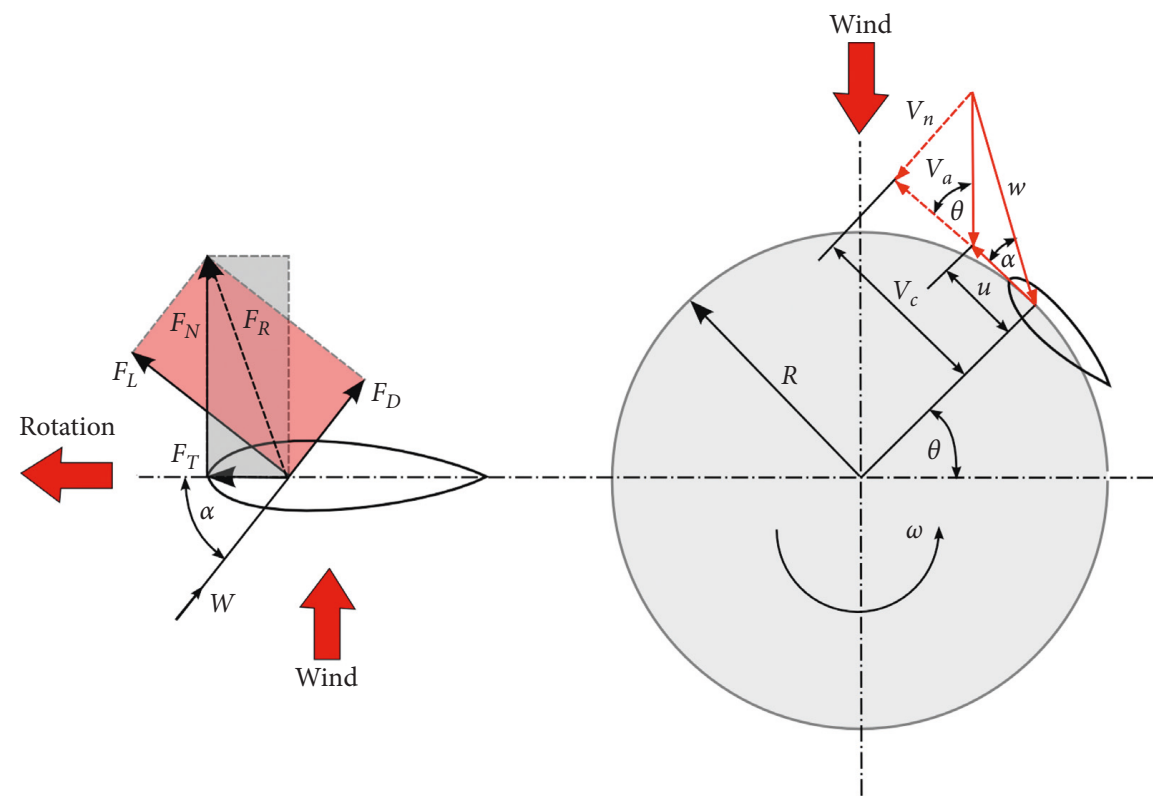

Figure 2: Velocities and forces distributions of Darrieus turbine airfoils.

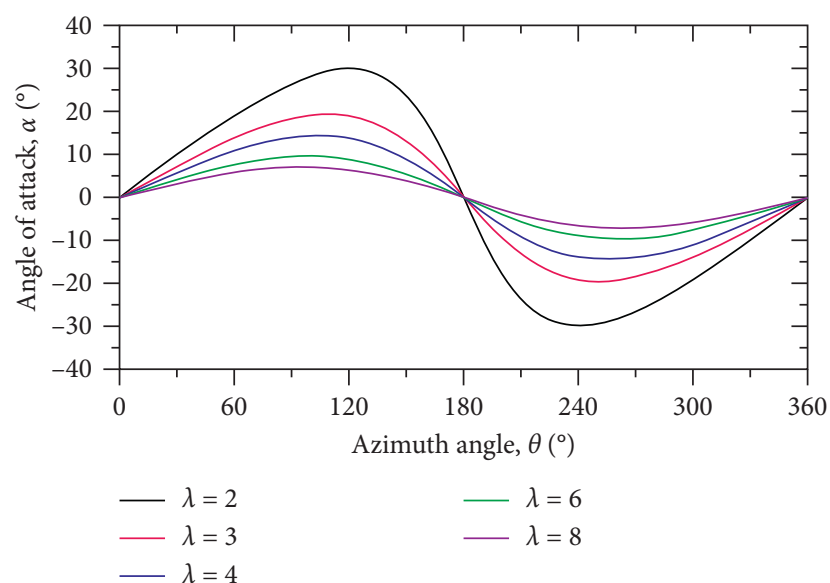

Figure 3: The change of azimuth angle $\theta$ with incident angle $\alpha$ for one revolution at various speed ratios $\lambda$.

Via grouping those factors, we will obtain some equations of the aerodynamic forces, torques, and power coefficients as follows:

$$
\begin{aligned}
& C_{m}=\frac{T}{(1 / 2) \rho A R U_{\infty}^{3},} \\
& C_{p}=\frac{P}{(1 / 2) \rho A U_{\infty}^{3}}, \\
& C_{x}=\frac{F_{n}}{(1 / 2) \rho A U_{\infty}^{2}}, \\
& C_{T}=\frac{F_{T}}{(1 / 2) \rho A U_{\infty}^{2}},
\end{aligned}
$$

$$
C_{m s}=\frac{T_{s}}{(1 / 2) \rho A R U_{\infty}^{2}},
$$

where $C_{p}$ and $C_{m}$ are the power coefficients and torque coefficients, respectively. Furthermore, $C_{x}$ is an axial force coefficient and $C_{T}$ is a tangential force coefficient. Readers must pay attention to the fact that all of these factors are dynamic parameters. This means that all of these factors have been studied through the rotations of the rotor. Although $C_{m s}$ is the static torques coefficient, it was defined within the static cases of the turbines like maintenance situations. Additionally, $C_{m s}$ is a very remarkable index to the self-starting capabilities of the turbines. In the recent study, all of these factors have been determined to get the complete force analysis over the sectional profile during the rotation and static conditions (as shown in Figure 4).

\section{Methodology and Model Validation}

The modeling plan and the strategy were introduced in this section to clarify the objectives of simulation estimation of the aerodynamic conduct of a Darrieus rotor using several profile sections of airfoil. The present work deals with symmetric and nonsymmetric airfoil shapes (3 airfoils), NACA 0021 (symmetric airfoil), S1046 (symmetric airfoil), and LS413 (nonsymmetric airfoil), as represented in Figure 5. The target of this work is to obtain the different forces and torsion dynamically and statically around the blades of the turbine. This will help the mechanical designers and manufacturers to build and construct a Darrieus turbine safely. The analysis of the turbine is introduced at different angular velocities with a fixed wind flow velocity equal to 


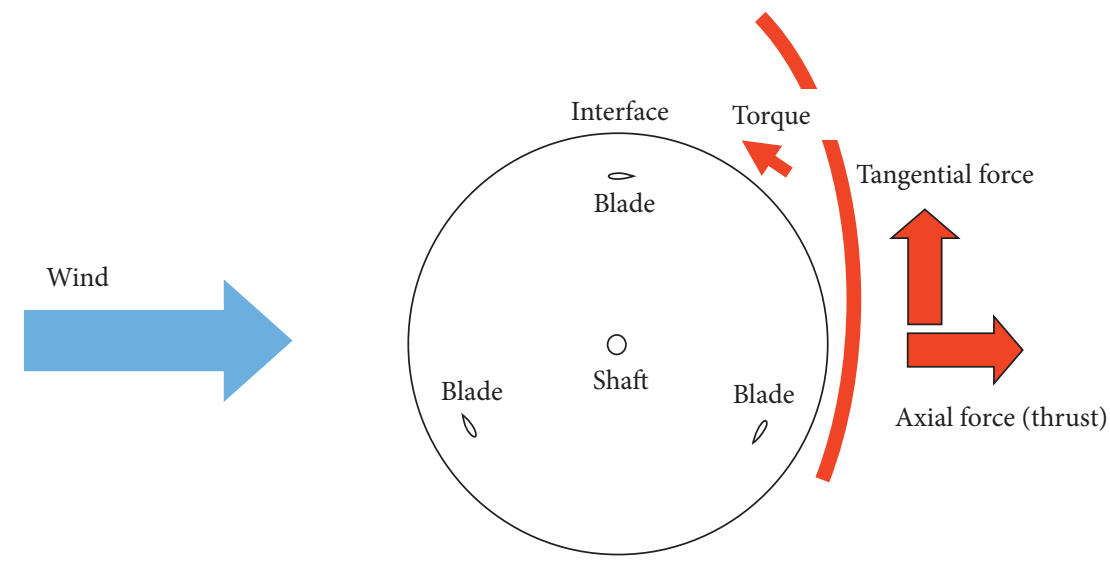

Figure 4: Distribution of various forces and torque impacting the Darrieus rotor.

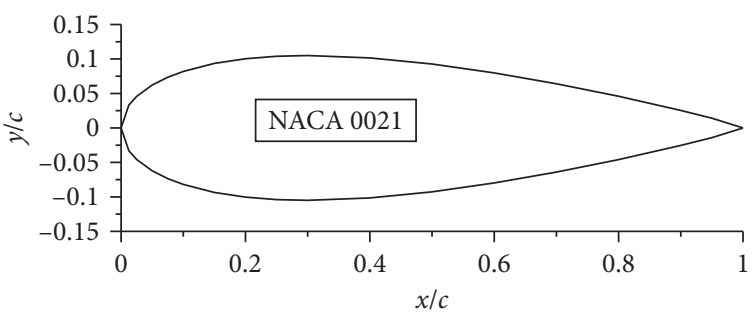

(a)

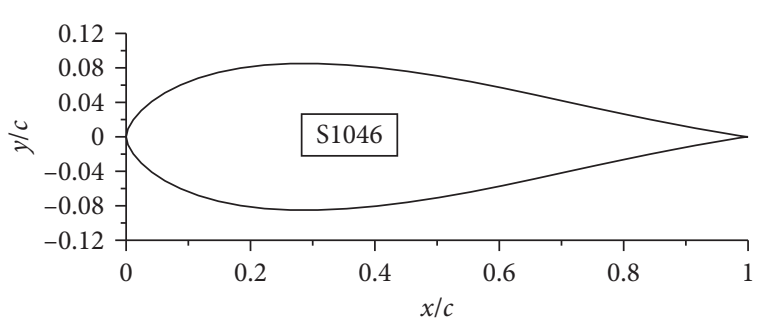

(b)

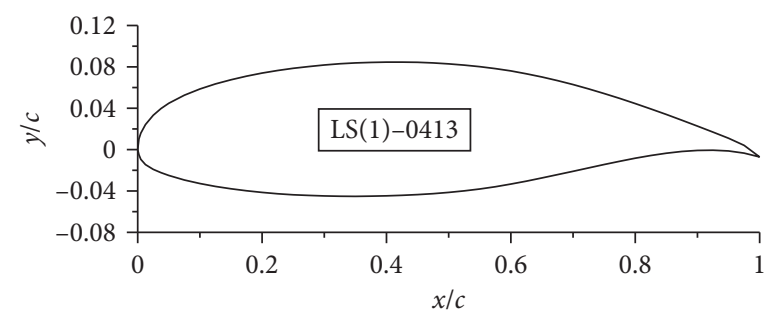

(c)

Figure 5: Airfoil shapes.

$9 \mathrm{~m} / \mathrm{s}$. The major geometrical characteristics of the turbine studied were summarized in Table 1.

In the first step in this work, an important task is to study the full numerical models with deep concern. The commercial ANSYS software (Fluent) has been applied in the present paper for all calculations that have been performed. In CFD techniques, a transient case study called "Reynolds Averaged Navier-Stokes" equations (URANS) was studied using the "SIMPLE algorithm" for the coupling of pressure velocity. Discretizations were executed by using the finite volume analysis with second-order upwind scheme for all factors. Incompressible continuity equation of unsteady flow can be written in tensorial formula as

$$
\frac{\partial u_{i}}{\partial t}+\frac{\partial u_{i}}{\partial x_{i}}=0
$$

and the momentum equation can be written as
TABle 1: Darrieus turbine descriptions.

\begin{tabular}{lc}
\hline Parameter & Specifications \\
\hline Blade profile & NACA 0021, S1046, LS413 \\
Number of blades $N$ & 3 \\
Blade chord length $c$ & $0.0833 \mathrm{~m}$ \\
Rotor radius $R$ & $0.5 \mathrm{~m}$ \\
Rotor height $H$ & $1 \mathrm{~m}$ (two-dimensional simulation) \\
Rotor solidity $\sigma$ & 0.25 \\
Tip-speed ratio $\lambda$ & $1: 3.5$ \\
Wind speed $U_{\infty}$ & $9 \mathrm{~m} / \mathrm{s}$ \\
\hline & $\frac{\partial u_{i}}{\partial x_{j}}=-\frac{\partial p}{\rho} \frac{\partial x_{i}}{\partial x_{i}}-\frac{\partial}{\partial x_{j}}\left[v\left(\frac{\partial u_{i}}{\partial x_{j}}+\frac{\partial u_{j}}{\partial x_{i}}-\frac{2}{3} \delta_{i j} \frac{\partial u_{i}}{\partial x_{i}}\right)\right]$ \\
& $+\frac{\partial}{\partial x_{j}}\left(-\bar{u}_{i} \grave{u}_{j}\right)$.
\end{tabular}




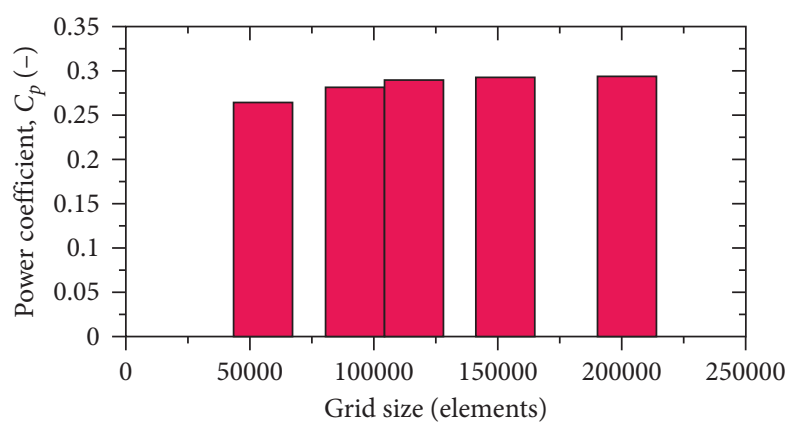

FIgURE 6: Mesh independence study by changing the power coefficient $C_{p}$ with grid size at $\lambda=3.3$.

During the dynamic forces calculation and by using the sliding mesh model (SMM), the 2D transient flow was executed to behold the physics of turbine rotations impacts. However, in the static case, sliding mesh model (SMM) is not required. Double tests on convergence were fulfilled. The first check is relying on the torque coefficients $C_{m}$ convergence criteria that it must be lower than $1 \%$. The second one is achieved by the residuals that should be lower than $10^{-5}$ at any physical time step (iteration). All the simulations introduced that five revolutions are needed to obtain the steady convergence states. Via the mean value, the results of the last revolution, power coefficient, and torque coefficient have been determined. The current study with ultimate subiterations of 70 to obtain the solutions convergence at all physical time steps was utilized. Computation accomplished by 8 -processor, $2.80 \mathrm{GHz}$ clock frequency PC needs a whole CPU time of about 350 minutes during five cycles. The accurate mesh evaluation was performed on one configuration that has three-blades NACA 0021 sectional profile blades at $\lambda=3$. An unstructured mesh was chosen for the full flow domain with accurate qualities.

Mesh on both sides of the interfaces boundaries has the same number of cell sizes to obtain quicker convergences exceptionally and the continuity equation. Density and quality of unstructured cells in 2D CFD domain were studied and read through different cell sizes ranging approximately within 55,000 and 200,000 cells. This work presents that more than 153,200 cells lead to a relative variance of the output quantities less than $1.049 \%$ as represented in Figure 6. A reasonable grid of 164,200 cells has been held over all the further results due to the calculating time.

A certain square CFD domain form with convenient dimensions was employed with a considerable ratio between the turbine diameter and the CFD domain lengths; that ratio equals 25 as represented in Figure 7. Within the stationary and rotating zones, the grids have been picked out as unstructured grid (see Figure 8). Six layers on the blades wall boundary with a growth rate of 1.4 have been accomplished to obtain a small normalized wall distance of $y+<3$. Wall functions have been used to be $y+<3$ through the simulations of the flow field with a fixed wind speed of $9 \mathrm{~m} / \mathrm{s}$ and it will be constant in the whole simulation in the present project. These techniques ware utilized in various applications by one of the authors of this paper in the drag and lift vertical turbines [15-19]. Cali et al. [20] offered a method that enhanced recognizing of the influences of panel arrangements and fibre orientations on sail performances. Fluid-structure-interaction (FSI) in a symmetric spinnaker was studied through an integrated CFD-CSM (Computational Structural Mechanics) analysis. Numerical simulations are also used to compare sail designs and to optimize sail parameters [21].

The CFD boundary conditions utilized in the simulations are given in Figures 7 and 8. Symmetry boundaries, velocity inlet, pressure outlet, and interfaces between the rotating and fixed boundaries were required as shown in Figures 7 and 8. In Table 2, a summery of the CFD boundary conditions and flow domain dimensions is introduced.

The turbulence models validation was the second step in the simulations after accomplishing the grid independence tests. The aerodynamic rapprochement and proximity of power coefficients $C_{p}$ between the current model and experimental results have been published by Castelli et al. [5]. It was carried out as well as other CFD outputs $[5,7,12,18,22]$ as shown in Figure 9. The comparison was quantitative and qualitative. Furthermore, it is noted that there are accurate, reasonable, and considerable agreements between the present CFD simulations and the experimental results [5] in the determinations of the power output coefficients. The realizable $k-\varepsilon$ turbulence model is used in the present CFD model with the aid of standard wall function. From this comparison, it is noted that the current CFD methodology is an acceptable strategy to calculate and simulate the performance of the $\mathrm{H}$-rotor Darrieus turbines. The studied H-rotor blade vertical axis wind turbines in this work operate in Reynolds number flow field of the order of $10^{5}$. The flow speed, $U_{\infty}$, is $9 \mathrm{~m} / \mathrm{s}$ during the simulations and the Reynolds number is equal to approximately $0.3 \times 10^{5}$ established (chord base), $c=0.05 \mathrm{~m}$. The inlet flow turbulence intensity equals $5 \%$ and turbine hydraulic diameter is $1 \mathrm{~m}$.

This turbulence model (realizable $k-\varepsilon$ turbulence model) was introduced and improved by Shih et al. [23]. This model is relying on new transport equations for the turbulent dissipation rates that upgrade the features of the turbulence model. A model critical coefficient $\left(C_{m u}\right)$ that is already constant in the standard $k-\varepsilon$ model is variable in 


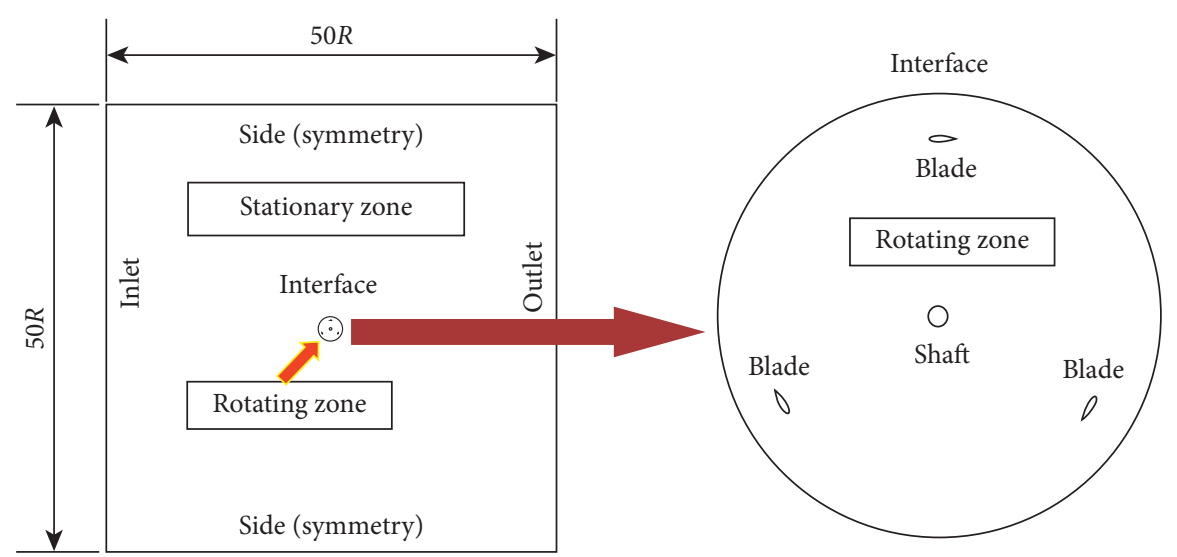

FIgURE 7: Flow domain.

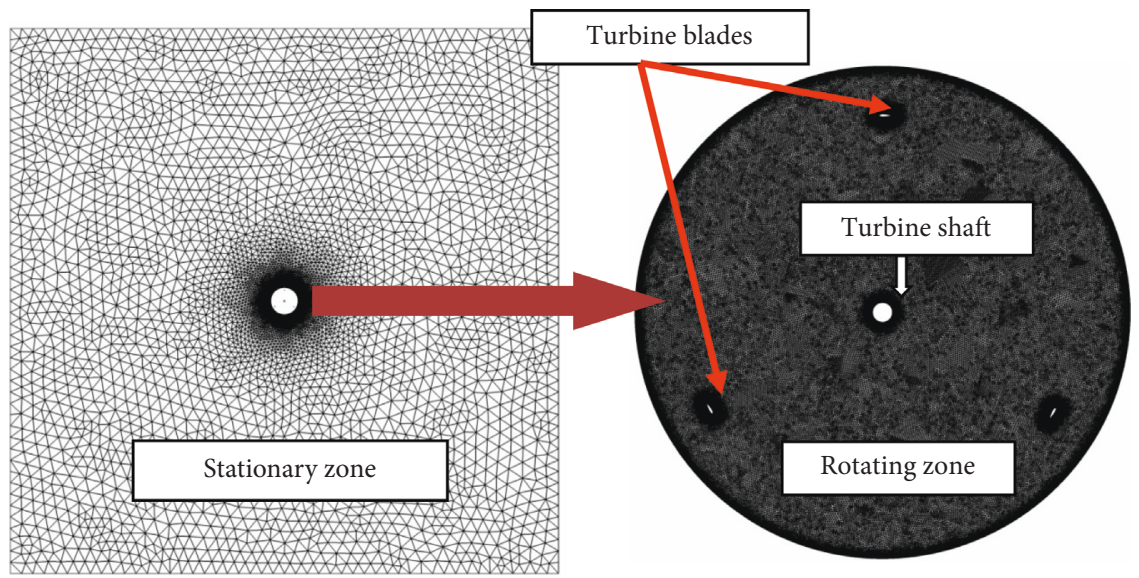

FIGURE 8: Unstructured grid.

TABLE 2: Mesh and boundary conditions used in the current CFD work.

\begin{tabular}{lc}
\hline Parameter & Description \\
\hline Flow domain & Square $(50 R \times 50 R)$ \\
Interface/type & Sliding/conformal \\
Grid/type & Unstructured/tri \\
Elements & 164,200 \\
Fluid & Air \\
Turbulence model & $k$ - $\varepsilon$ realizable \\
Inlet & Velocity inlet \\
Outlet & Pressure outlet \\
Shaft & No-slip wall \\
Blades & No-slip wall \\
Side & Symmetry \\
Residuals RMS criteria & $1 \times 10^{-5}$ \\
\hline
\end{tabular}

the realizable $k-\varepsilon$ turbulence model. This variable coefficient is function in the mean flow conditions and turbulence properties.

In the rotating flows, separated flow, and flow stream under strong levels of adverse pressure gradient, the realizable $k-\varepsilon$ turbulence model introduces a superb performance. In addition, this turbulence model also solves essential problems in the standard $k-\varepsilon$ model, especially when the flow features includes rotation, vortices, and extreme curvature in the streamline.

The word "realizable" means that the model accepts the flow constraints and the mathematical analysis on 


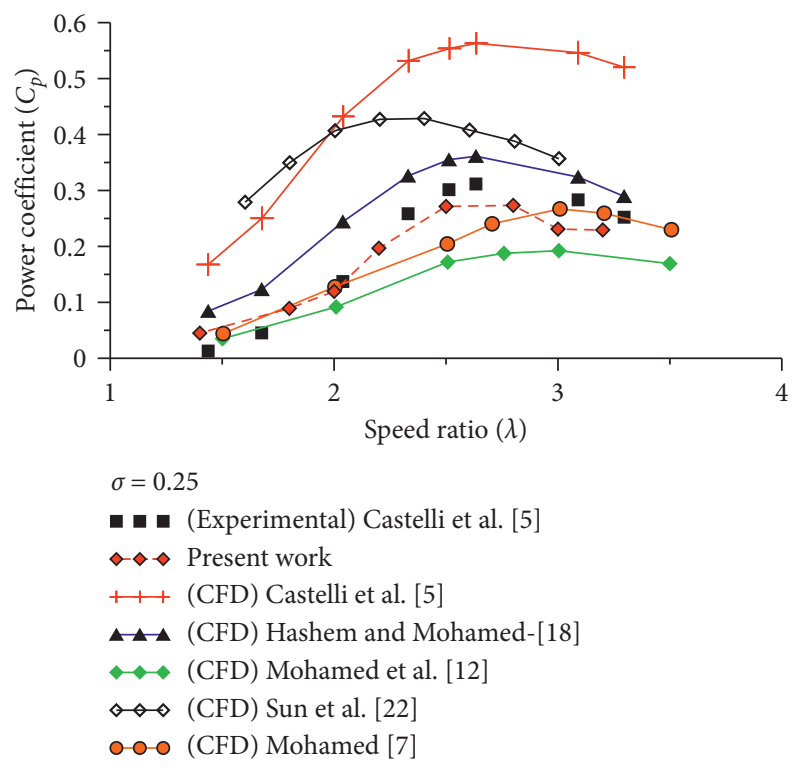

FIGURE 9: Present CFD study versus the experimental results of [5] and other CFD results for a Darrieus turbines [5, 7, 12, 18, 22].

harmonious and normal stresses with the turbulent flow physics. By using $v_{t}=\mu_{t} / \rho$, the result introducing negative values for the normal stress is obtained $\overline{u^{2}}$, that are positive quantities "nonrealizable." To get the realizability, $\left(C_{\mu}\right)$ must be variable by considering it to be a function of the turbulence characteristics. Transport equations of $k$ and $\varepsilon$ in the realizable $k-\varepsilon$ model are written as follows:

$$
\begin{aligned}
\frac{\partial}{\partial t}(\rho k)+\frac{\partial}{\partial x_{i}}\left(\rho k u_{j}\right)= & \frac{\partial}{\partial x_{i}}\left[\left(\mu+\frac{\mu_{t}}{\sigma_{k}}\right) \frac{\partial k}{\partial x_{j}}\right]+G_{k}+G_{b} \\
& -\rho \varepsilon-Y_{M}+S_{k}, \\
\frac{\partial}{\partial t}(\rho \varepsilon)+\frac{\partial}{\partial x_{j}}\left(\rho \varepsilon u_{j}\right)= & \frac{\partial}{\partial x_{j}}\left[\left(\mu+\frac{\mu_{t}}{\sigma_{\varepsilon}}\right) \frac{\partial \varepsilon}{\partial x_{j}}\right]+\rho C_{1} S_{t} \\
& -\rho C_{2} \frac{\varepsilon^{2}}{k+\sqrt{v \varepsilon}}+C_{1 \varepsilon} \frac{\varepsilon}{k} C_{3 \varepsilon} G_{b}+S_{t},
\end{aligned}
$$

where

$$
\begin{aligned}
C_{1} & =\max \left[0.43, \frac{\eta}{\eta+5}\right], \\
\eta & =S \frac{k}{\varepsilon},
\end{aligned}
$$

where $G_{k}$ is a function of the generated turbulence kinetic energy; $G_{b}$ is a function of the generated turbulence kinetic energy; $Y_{M}$ is the fluctuating incompressible diffusion; $\sigma_{k}$ and $\sigma_{\varepsilon}$ are functions of the turbulent Prandtl numbers; $S_{k}$ and $S_{\varepsilon}$ are user-defined source terms.

\section{Results and Discussions}

A lot of parameters are influencing aerodynamically the performance of the vertical axis wind turbines. The essential forces created over any airfoil are the drag forces and lift forces. Lift forces to drag forces ratio is a function of turbines solidities, airfoil section profiles, speed ratios, and wind speeds. This paper studies the dynamic and static forces on the airfoils of the turbines through the rotations and during the static condition, like axial forces coefficient $\left(C_{x}\right)$, tangential forces coefficient $\left(C_{T}\right)$, torque coefficient $\left(C_{m}\right)$, and static torque coefficient $\left(C_{m s}\right)$. The following results can assist the designers and manufacturers to choose appropriate materials and convenient dimensions of different elements of the turbines. All of those coefficients will be determined from the equations [5-9] for the several sectional airfoil sectional profiles, NACA 0021, LS413, and S1046.

In Figure 10, the results indicate that turbines that consist of LS413 airfoil have higher torque coefficients. Equation (5) is used to calculate the torque coefficient that is a dynamic moment. So, this shows that turbines introduce larger power outputs that were determined by (6). Moreover, readers here should not pay attention to negative signs showing the direction of turbine rotation. However, static torques can be calculated by (9) and it introduces the capability of turbine self-starting. Additionally, and at the maintenance terms, turbines will be stationary and the static torques $\left(C_{m s}\right)$, static thrusts $\left(C_{x s}\right)$, and static tangential forces $\left(C_{T s}\right)$ will impact the several parts and probably failures will occur. Figure 11 introduces a rapprochement between the turbines with several 


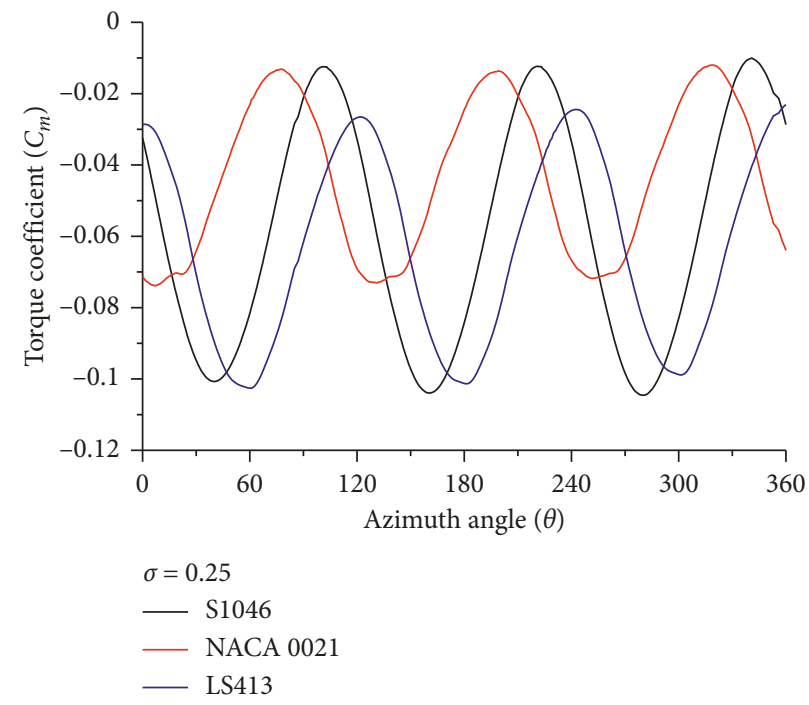

FiguRE 10: Instantaneous dynamic torque coefficient on the Darrieus turbine.
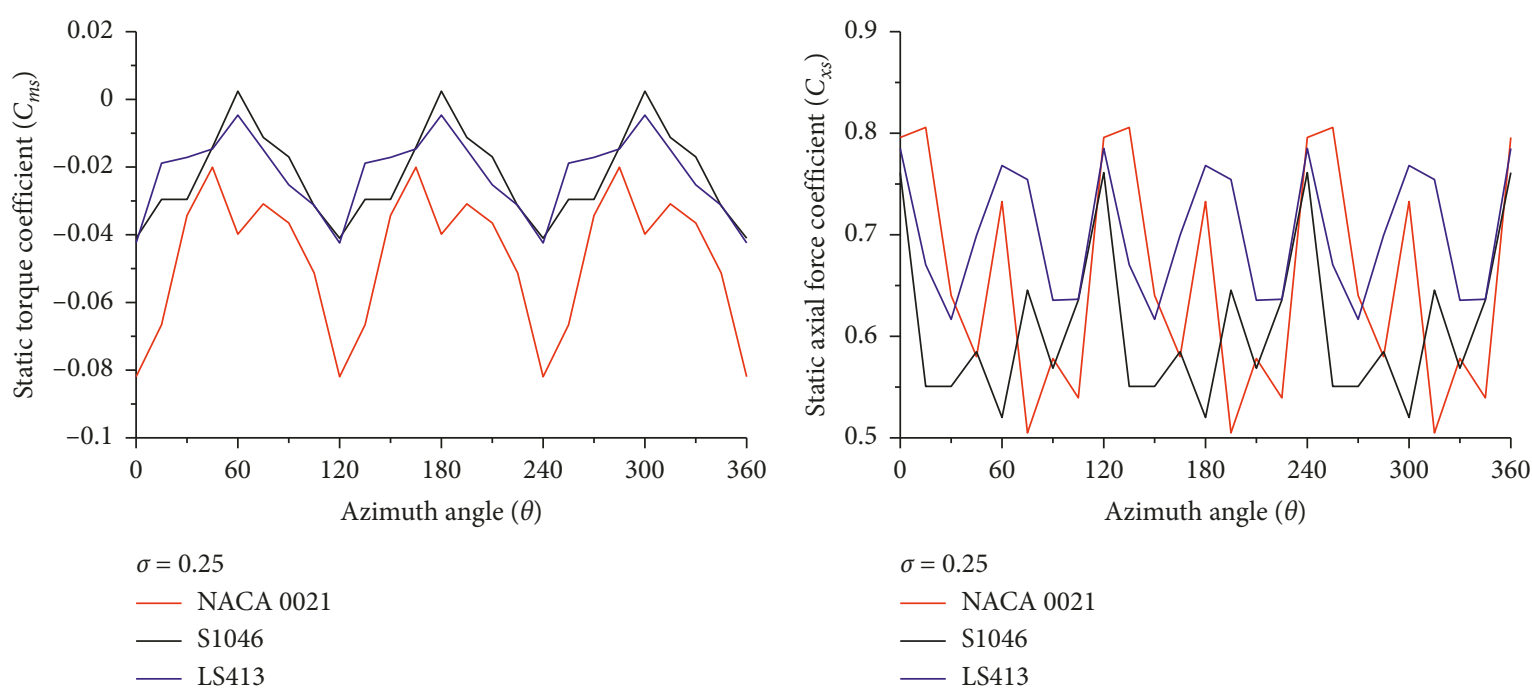

(a)

(b)

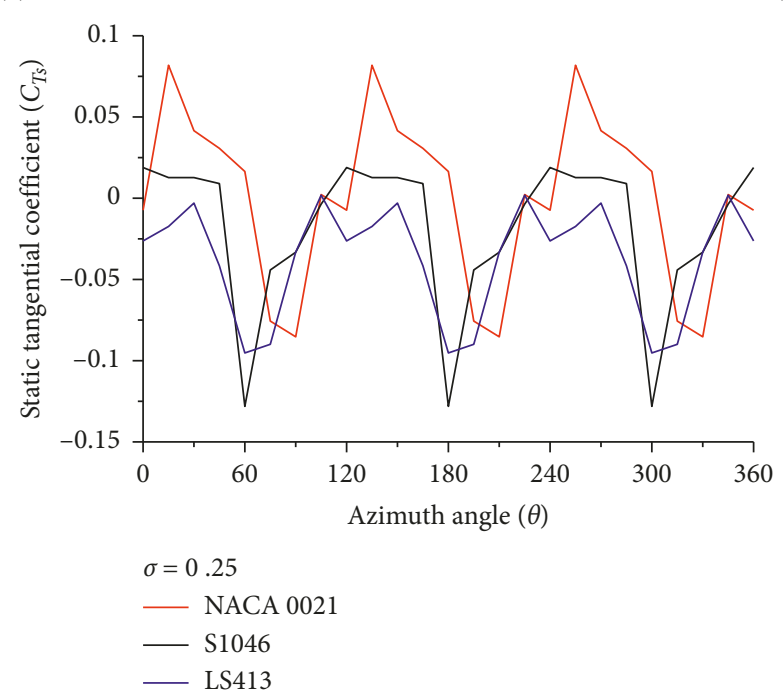

(c)

FIgURE 11: Static torque, static axial force, and static tangential force coefficient on the Darrieus turbine. 


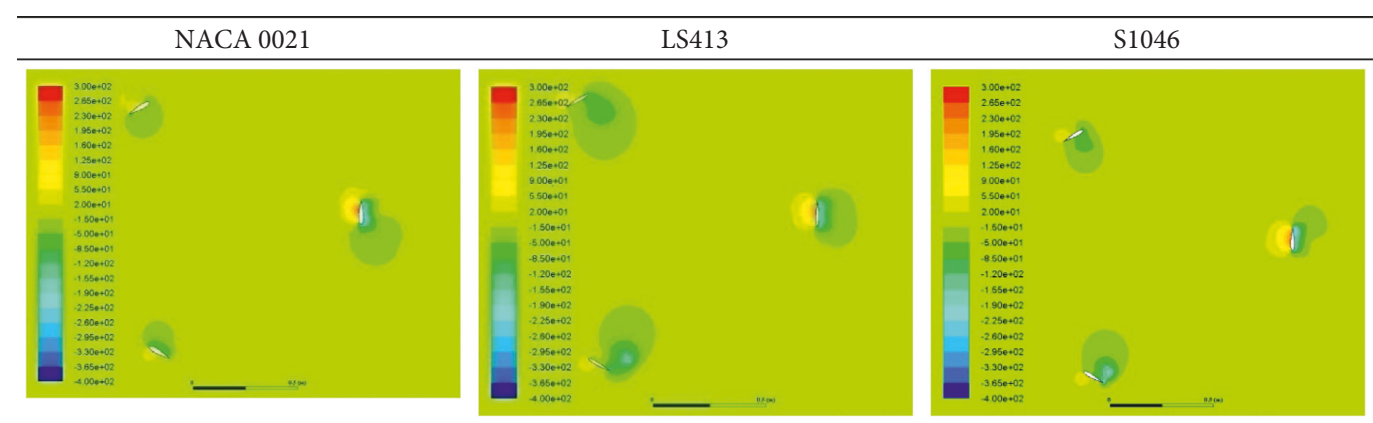

Pressure distribution at fixed conditions, 0 degrees

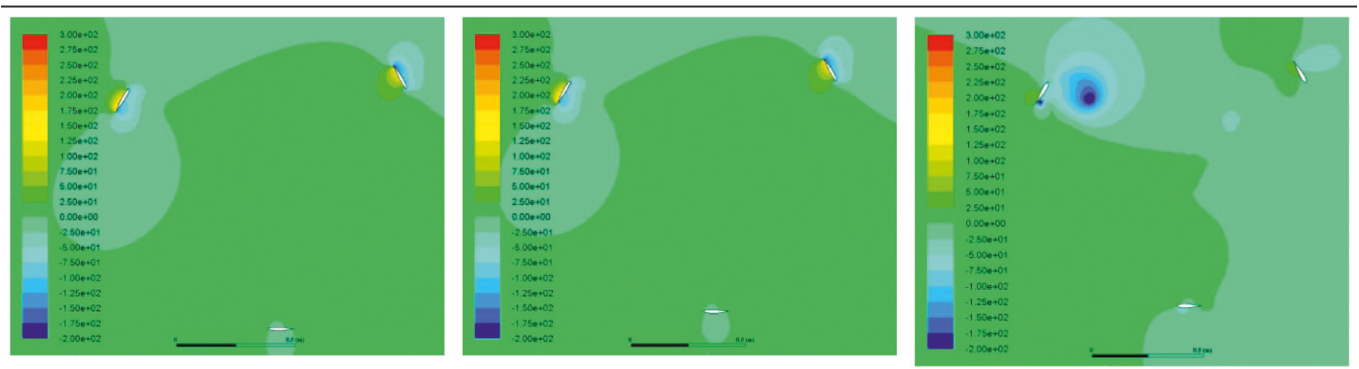

Pressure distribution at fixed conditions, 30 degrees

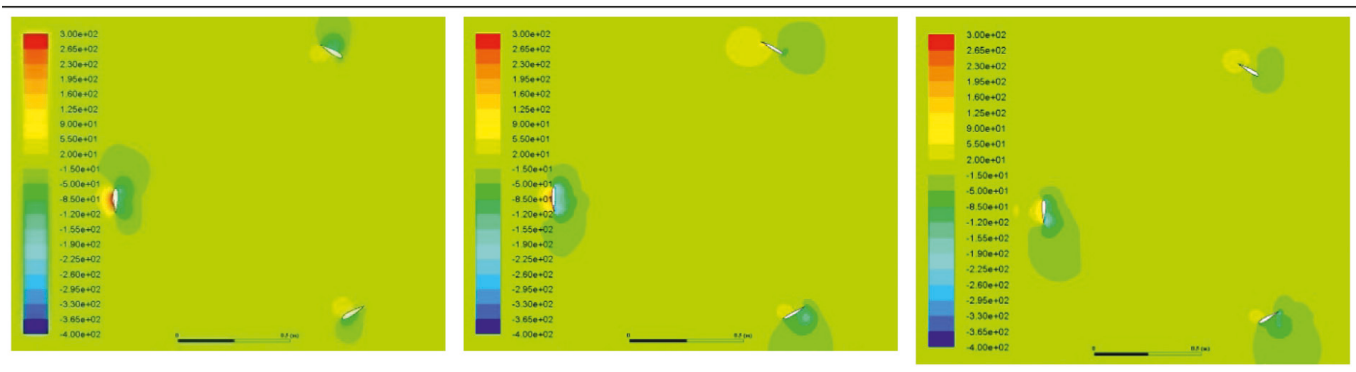

Pressure distribution at fixed conditions, 60 degrees
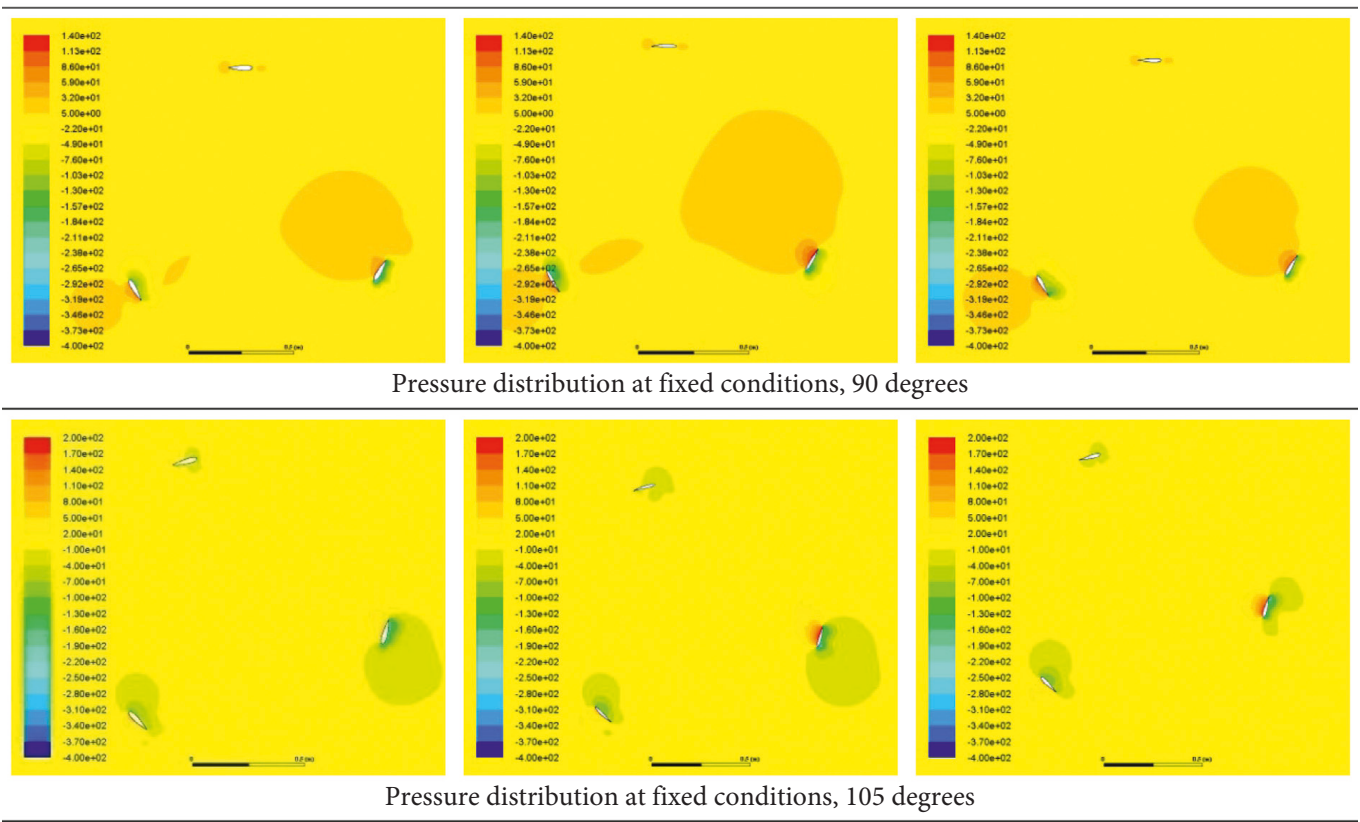

FIgURe 12: Pressure distribution at fixed conditions at different configurations. 


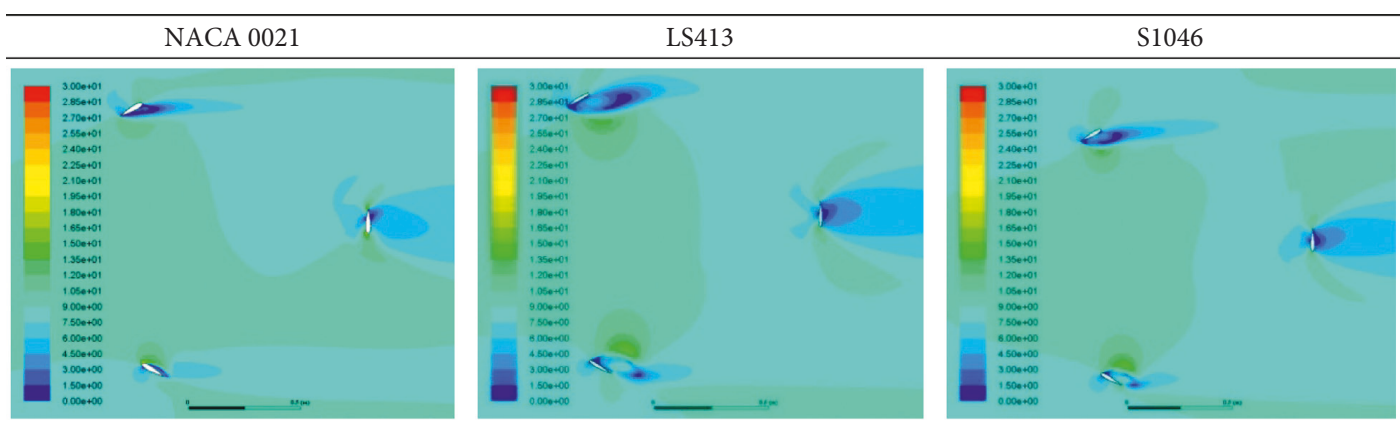

Velocity distribution at fixed conditions, 0 degrees

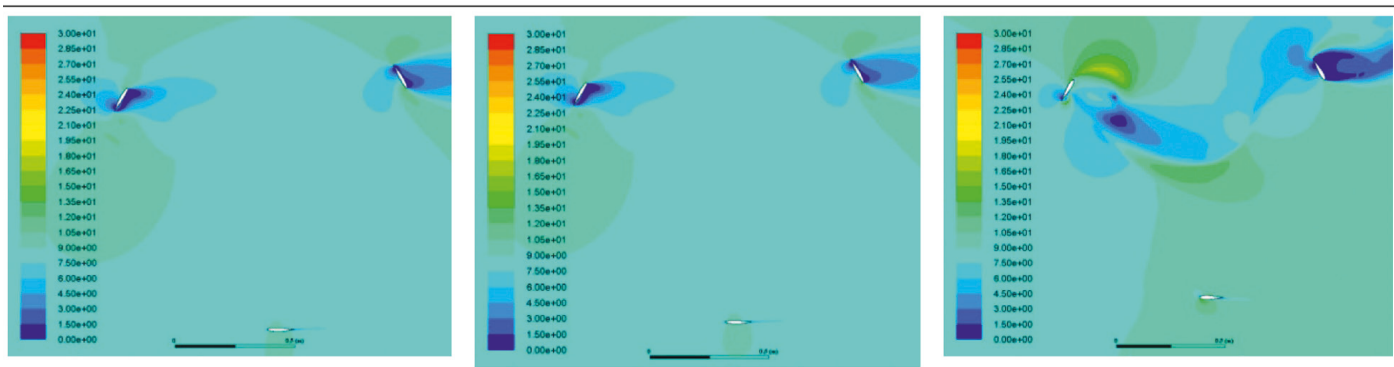

Velocity distribution at fixed conditions, 30 degrees

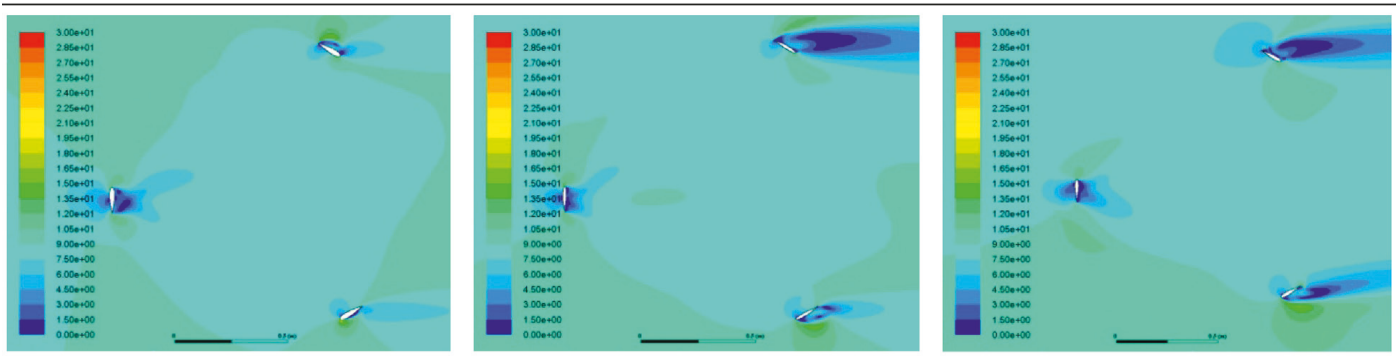

Velocity distribution at fixed conditions, 60 degrees

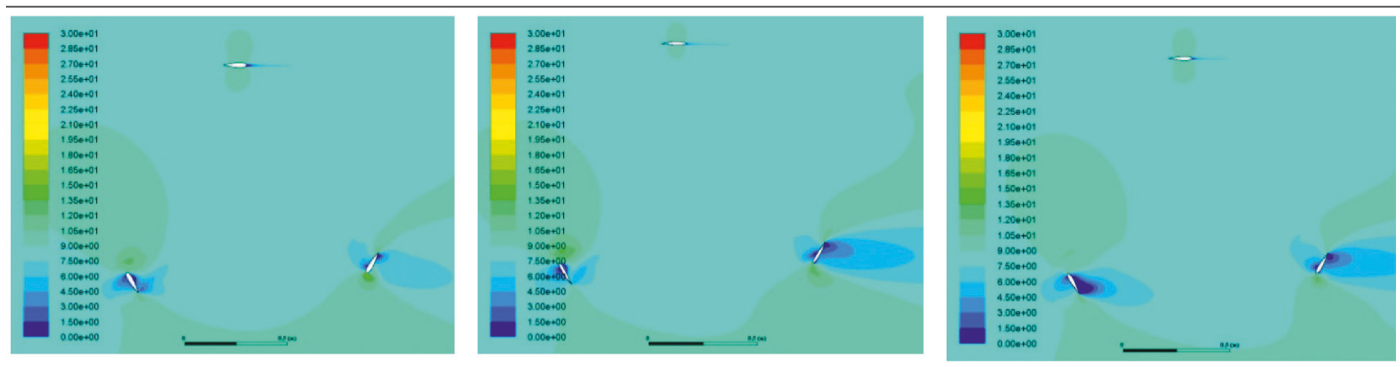

Velocity distribution at fixed conditions, 90 degrees

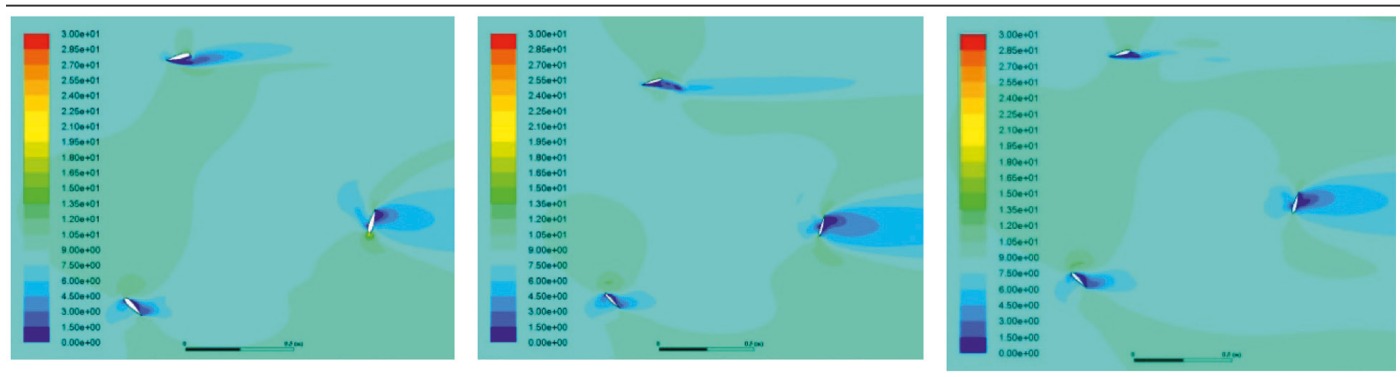

Velocity distribution at fixed conditions, 105 degrees

FIgURE 13: Velocity distribution at fixed conditions at different configurations. 


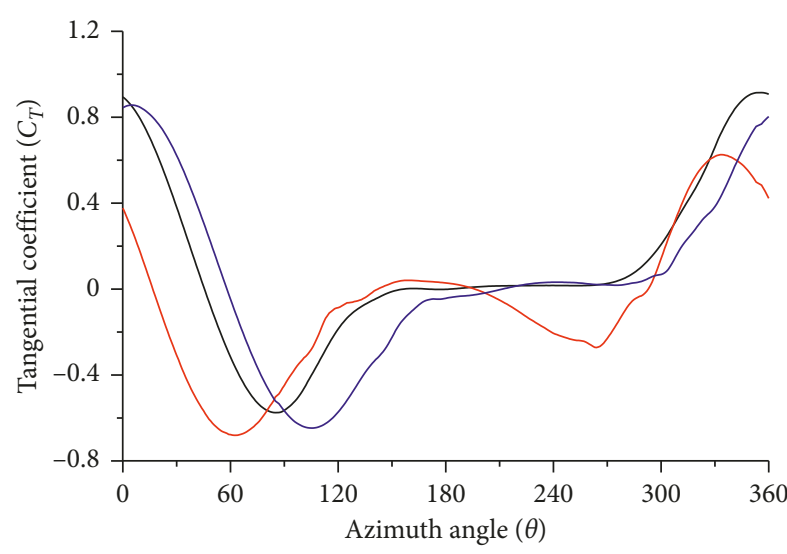

Blade 1

$\lambda=3$

- S1046

— LS413

- NACA 0021

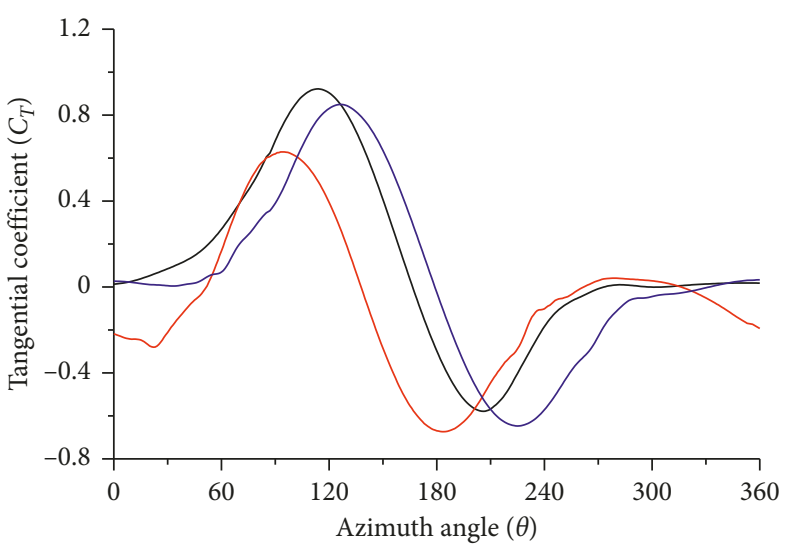

Blade 2

$\lambda=3$

- S1046

- LS413

— NACA 0021

(a)

(b)

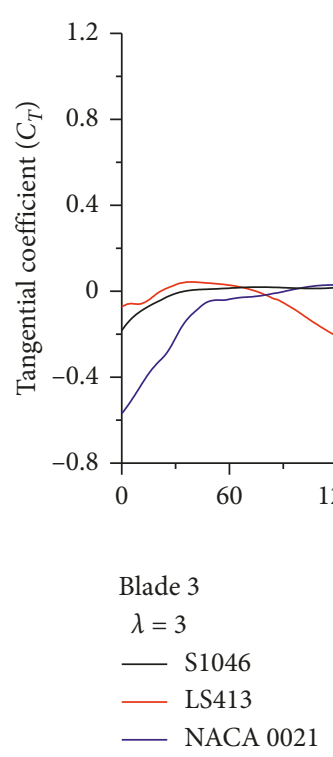

(c)

FIGURE 14: Instantaneous dynamic tangential force coefficients on the Darrieus rotor located at every blade.

sectional profile airfoils (NACA 0021, LS413, and S1046) for that aerodynamic forces coefficient. It is clear that there is no massive variation in the static force coefficients between the various H-rotor Darrieus turbines apart from the static torque coefficient of S1046 which is less than the other. This gives the advantage that the static torsion on the turbine is smaller with S1046; however, the turbine that consists of S1046 has the disadvantage of less self-starting ability. In Figures 12 and 13, the pressure and velocity distributions are introduced, respectively, for the different turbine designs of the static conditions $(0,30,60,90$, and 105 degrees).
The dynamic loads also are very significant and important during the mechanical design and manufacturing of the Darrieus turbine; therefore, the authors investigated the instantaneous tangential force and axial force coefficients as presented in Figures 14 and 15. The study analyzed the forces at every one degree of the azimuth angle for a revolution and also studied the forces for every blade in the turbine individually to show the dynamic stresses and loads on every blade instantaneously. Form the figures, it is also noted that the S1046 blades have higher maximum tangential force and axial force coefficients than the other airfoils. This means that if the designer selects the turbine 


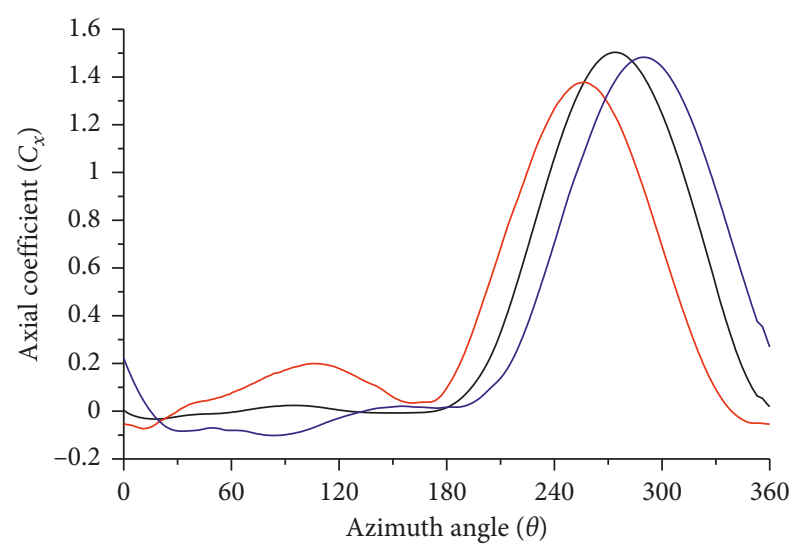

Blade 1

$\lambda=3$

- S1046

— LS413

- NACA 0021

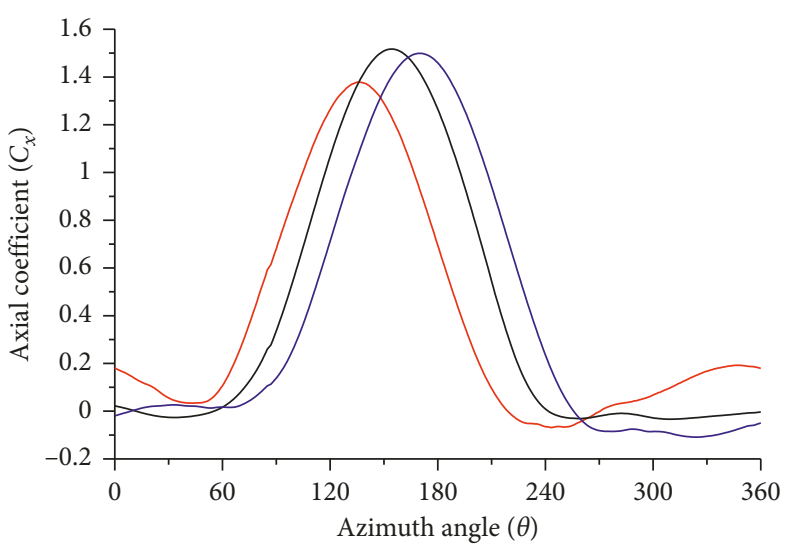

Blade 2

$\lambda=3$

- S1046

— LS413

— NACA 0021

(a)

(b)

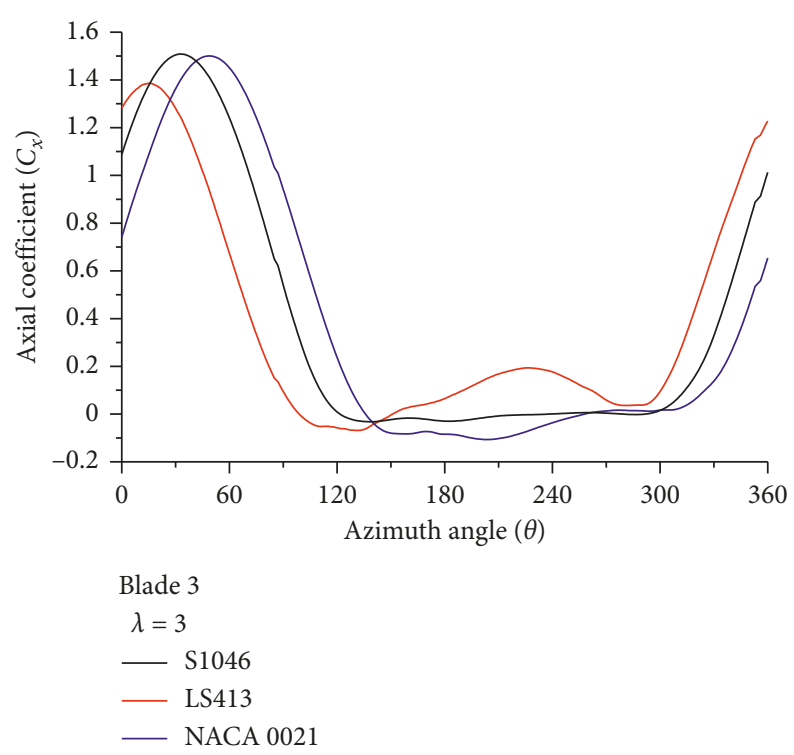

(c)

FIGURE 15: Instantaneous dynamic axial force coefficients on the Darrieus rotor located at every blade.

that consists of S1046, he should take into consideration the higher dynamic loads.

\section{Conclusions}

Vertical axis wind turbine (VAWT), especially Darrieus turbine, has the eligibility to work at low and weak wind speed conditions. However, it has the weakness of minimal aerodynamic performances with comparison to horizontal axis wind turbines. The current paper's target is to assess the aerodynamic performance of the Darrieus H-rotors under the optimal blade airfoils selected by the previous work and introduce some details about the different forces generated on the turbine blades during either the rotation or the stagnant (static) conditions. CFD simulations based and depending on the finite volume analysis have been used in this work under the interface of the ANSYS fluent commercial code. Accordingly, some findings have been concluded:

(i) Three airfoils that are appropriate for Darrieus turbine (H-rotor) are examined, which have higher and suitable aerodynamic performance. It is found that NACA 0021, S-1046, and LS413 are the most suitable airfoils in the literatures. These airfoils are symmetric airfoils such as NACA 0021 and S-1046; however, LS413 is a nonsymmetric one. 
(ii) The $k-\varepsilon$ turbulence model has been utilized in the present CFD study with the support of standard wall function.

(iii) Quantitatively and qualitatively, validation is introduced in this paper and it is noted that there is an agreeable approbation between the present CFD simulations and experimental data [5] during the calculation of the power output coefficients. From this comparison, it is noted that current computational fluid dynamic methodology is a precise strategy to calculate aerodynamically the performance of a Darrieus turbine.

(iv) Axial force coefficients $\left(C_{x}\right)$, tangential force coefficients $\left(C_{T}\right)$, torque coefficients $\left(C_{m}\right)$, and static torque coefficients $\left(C_{m s}\right)$ have been checked in the current work as dynamic and static forces indicators on the blades during the rotation and the static conditions.

(v) The results indicated that turbines that consist of LS413 sectional profiles have higher dynamic torque coefficients; this deduces that turbines will introduce a high power output in the normal rotation conditions.

(vi) In the maintenance time and the static conditions, the turbines will be stationary and the static torques $\left(C_{m s}\right)$, static thrusts $\left(C_{x s}\right)$, and static tangential forces $\left(C_{T s}\right)$ are the indicators for the different stress affecting the different parts of the turbine. The results indicated that, apart from the S1046 static torque coefficients, there is no massive difference in the aerodynamic static force between the two turbines which is less than the other.

(vii) Low static torque gives an advantage that the static torsion on the turbine is smaller with S1046; however, the turbine that has been constructed with S1046 has some disadvantages such as the reduced ability of self-starting.

(viii) The results represented that the S1046 blades have higher maximum tangential force and axial force coefficients than the other airfoils. This means that if the designer selects the turbine that consists of S1046, he should take into consideration the higher dynamic loads.

\section{Nomenclature}

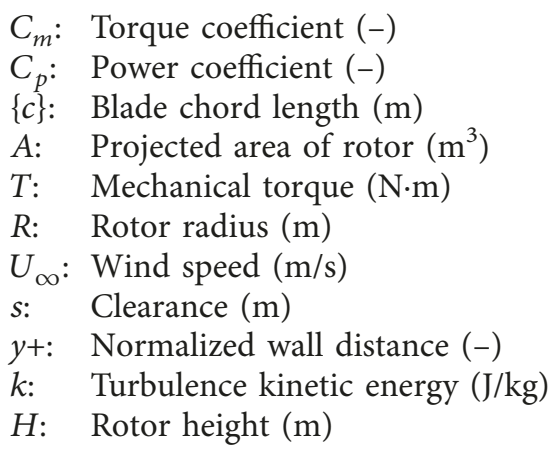

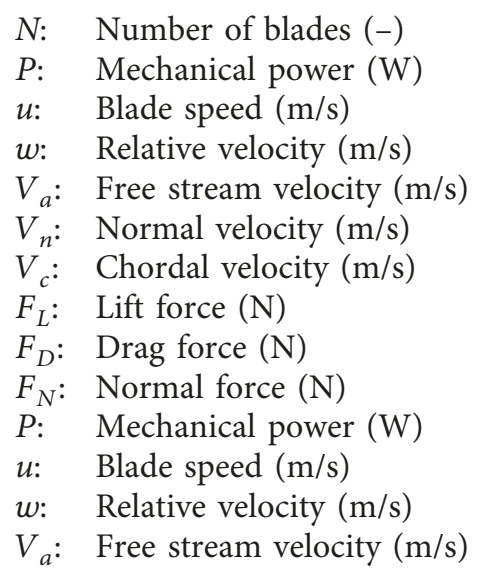

\section{Abbreviations}

URANS: Unsteady Reynolds Averaged Navier-Stokes

SMM: $\quad$ Sliding mesh model

VAWT: Vertical axis wind turbine

HAWT: Horizontal axis wind turbine

CFL: Courant-Friedrichs-Lewy

CFD: $\quad$ Computational fluid dynamics

DMST: Double multiple stream tube

SIMPLE: Semi-implicit method for pressure-linked equations

CFL: Courant-Friedrichs-Lewy

Greek Symbols

$\alpha$ : Angle of attack $\left({ }^{\circ}\right)$

$\sigma$ : Rotor solidity (-)

$\mu$ : Dynamic viscosity $(\mathrm{kg} / \mathrm{m} \cdot \mathrm{s})$

$\mu_{t}$ : Eddy viscosity $(\mathrm{kg} / \mathrm{m} \cdot \mathrm{s})$

$\lambda$ : Tip-speed ratio $(-)$

$\theta$ : Azimuth angle $\left({ }^{\circ}\right)$

$\omega$ : Angular velocity ( $\mathrm{rad} / \mathrm{s})$

$\varepsilon$ : Turbulence dissipation rate $(\mathrm{J} / \mathrm{kg} \cdot \mathrm{s})$

$v_{t}$ : Turbulence kinematic viscosity $\left(\mathrm{m}^{2} / \mathrm{s}\right)$

$\gamma$ : Inlet semiopen angle $\left(^{\circ}\right)$

$\rho:$ Density $\left(\mathrm{kg} / \mathrm{m}^{3}\right)$

Subscripts

$i, j$ : Temporal and spatial tensors

$$
\begin{aligned}
& \text { Superscripts } \\
& \overline{:} \text { Mean } \\
& \therefore \text { Fluctuating. }
\end{aligned}
$$

\section{Data Availability}

The data used to support the findings of this study are available from the corresponding author upon request.

\section{Conflicts of Interest}

The authors declare that they have no conflicts of interest.

\section{Acknowledgments}

This project and corroboration were supported financially by the University of Bisha. 


\section{References}

[1] E. Hau, Wind Turbines: Fundamentals, Technologies, Application, Economics, Springer-Verlag, Berlin, Heidelberg, 3rd edition, 2006.

[2] S. Takahashi, J. Hamada, and Y. Takashi, "Numerical and experimental studies of airfoils suitable for vertical axis wind turbines and an application of wind-energy collecting structure for higher performance," in Proceedings of theThe Fourth International Symposium on Computational Wind Engineering, pp. 327-330, Yokohama, Japan, July 2006.

[3] M. Mukinovic, G. Brenner, and A. Rahimi, "Analysis of vertical axis wind turbines," in New Results in Numerical and Experimental Fluid Mechanics VII, Springer, Berlin, Germany, 2010.

[4] V. Kumar, M. Paraschivoiu, and I. Paraschivoiu, "Low Reynolds number vertical axis wind turbine for mars," Wind Engineering, vol. 34, no. 4, pp. 461-476, 2010.

[5] M. R. Castelli, A. Englaro, and E. Benini, "The Darrieus wind turbine: proposal for a new performance prediction model based on CFD," Energy, vol. 36, no. 8, pp. 4919-4934, 2011.

[6] P. Sabaeifard, H. Razzaghi, and A. Forouzandeh, "Determination of vertical axis wind turbines optimal configuration through CFD simulations," in Proceedings of the 2012 International Conference on Future Environment and Energy, vol. 28, pp. 109-113, Singapore, November 2012.

[7] M. H. Mohamed, "Performance investigation of H-rotor Darrieus turbine with new airfoil shapes," Energy, vol. 47, no. 1, pp. 522-530, 2012.

[8] A. M. El Baz, A. R. Refaey, Y. Mohannad, and A. W. Y. Mohammed, "Computational modelling of H-type Darrius vertical axis wind turbine with multi element airfoil blades," in Proceedings of the IICFD11:2013: International Conference of Fluid Dynamics, pp. 1-9, Alexandria, Egypt, December 2013.

[9] M. H. Mohamed, "Impacts of solidity and hybrid system in small wind turbines performance," Energy, vol. 57, pp. 495504, 2013.

[10] F. Kanyako and I. Janajreh, "Numerical investigation of four commonly used airfoils for vertical axis wind turbine," ICREGA'14-Renewable Energy: Generation and Applications, Springer Proceedings in Energy, Springer, Berlin, GermanySpringer, 2014 .

[11] F. Trivellato and M. R. Castelli, "On the courant-FriedrichsLewy criterion of rotating grids in $2 \mathrm{D}$ vertical-axis wind turbine analysis," Renewable Energy, vol. 62, pp. 53-62, 2014.

[12] M. H. Mohamed, A. M. Ali, and A. A. Hafiz, "CFD analysis for H-rotor Darrieus turbine as a low speed wind energy converter," Engineering Science and Technology, an International Journal, vol. 18, no. 1, pp. 1-13, 2015.

[13] A. Bianchini, F. Balduzzi, G. Ferrara, and L. Ferrari, "Virtual incidence effect on rotating airfoils in Darrieus wind turbines," Energy Conversion and Management, vol. 111, pp. 329-338, 2016.

[14] K. Watanabe, S. Takahashi, and Y. Ohya, "Application of a diffuser structure to vertical-axis wind turbines," Energies, vol. 9, no. 6, p. 406, 2016.

[15] A. Ramadan, K. Yousef, M. Said, and M. H. Mohamed, "Shape optimization and experimental validation of a drag vertical axis wind turbine," Energy, vol. 151, pp. 839-853, 2018.

[16] M. Mohammadi, M. Lakestani, and M. H. Mohamed, "Intelligent parameter optimization of savonius rotor using artificial neural network and genetic algorithm," Energy, vol. 143, pp. 56-68, 2018.
[17] I. Hashem, M. H. Mohamed, and A. A. Hafiz, "Aero-acoustics noise assessment for wind-lens turbine," Energy, vol. 118, pp. 345-368, 2017.

[18] I. Hashem and M. H. Mohamed, "Aerodynamic performance enhancements of H-rotor Darrieus wind turbine," Energy, vol. 142, pp. 531-545, 2018.

[19] M. H. Mohamed, G. Janiga, and D. Thévenin, "Performance optimization of a modified Wells turbine using non-symmetric airfoil blades," in Proceedings of the ASME Turbo Expo 2008: Power for Land, Sea, and Air, Berlin, Germany, June 2008.

[20] M. Calì, S. M. Oliveri, U. Cella, M. Martorelli, A. Gloria, and D. Speranza, "Mechanical characterization and modeling of downwind sailcloth in fluid-structure interaction analysis," Ocean Engineering, vol. 165, pp. 488-504, 2018.

[21] J. B. Braun and L. Imas, "High fidelity CFD simulations in racing yacht aerodynamic analysis," in Proceedings of the $3 \mathrm{rd}$ High Performance Yacht Design Conference, pp. 2-4, Auckland, New Zealand, December 2008.

[22] X. Sun, Y. Wang, Q. An, Y. Cao, G. Wu, and D. Huang, "Aerodynamic performance and characteristic of vortex structures for Darrieus wind turbine. I. Numerical method and aerodynamic performance," Journal of Renewable and Sustainable Energy, vol. 6, no. 4, Article ID 043134, 2014.

[23] T.-H. Shih, W. W. Liou, A. Shabbir, Z. Yang, and J. Zhu, “A new $K-\epsilon$ Eddy viscosity model for high Reynolds number turbulent flows: model development and validation," Computers \& Fluids, vol. 24, no. 3, pp. 227-238, 1995. 


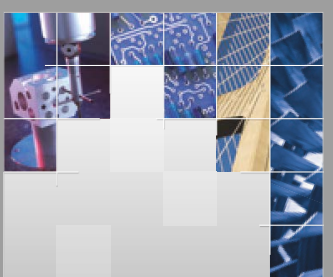

\section{Enfincering}
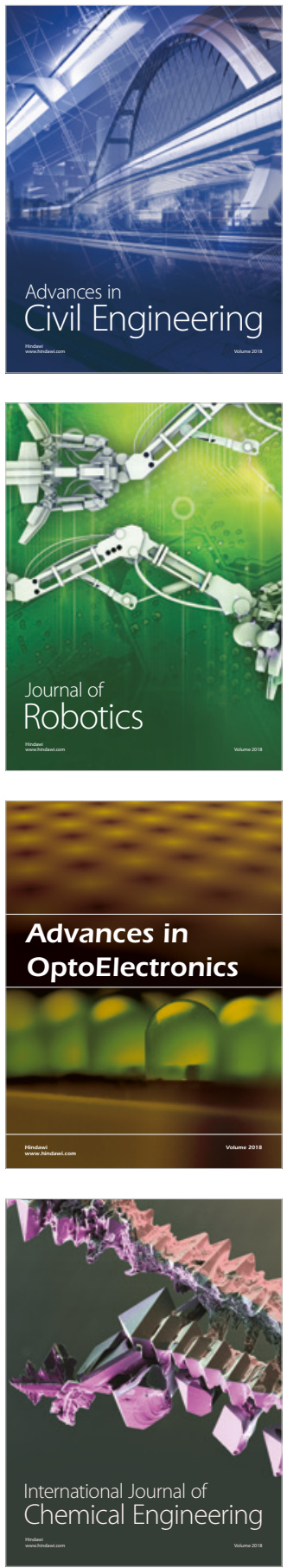

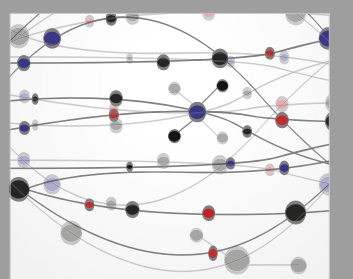

\section{Rotating \\ Machinery}

The Scientific World Journal

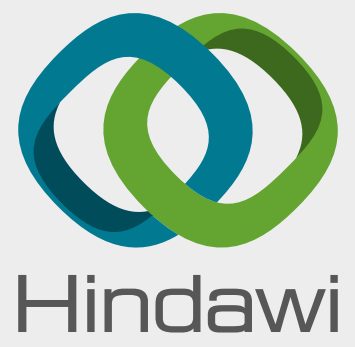

Submit your manuscripts at

www.hindawi.com
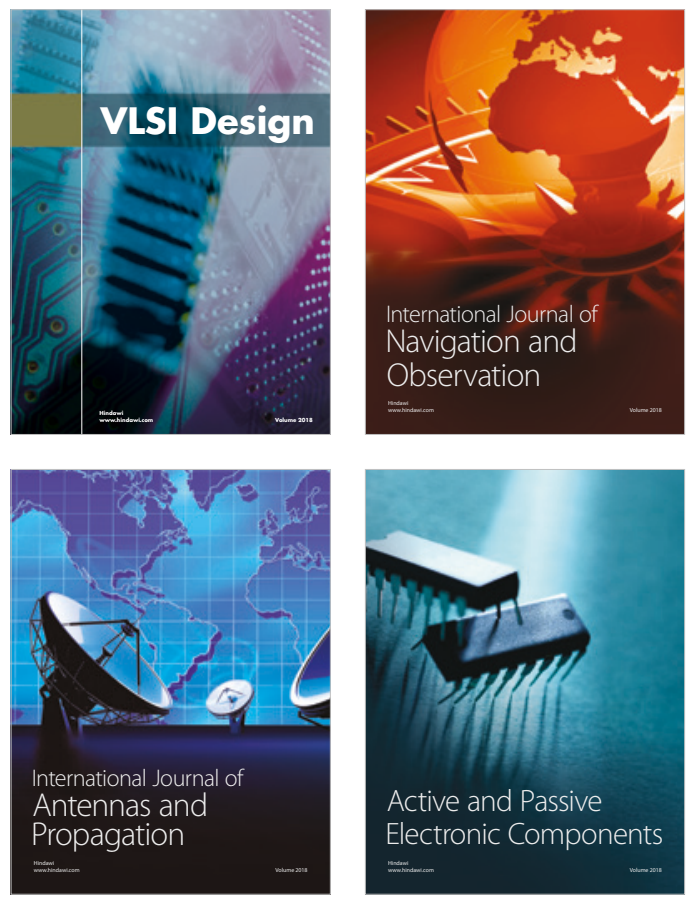
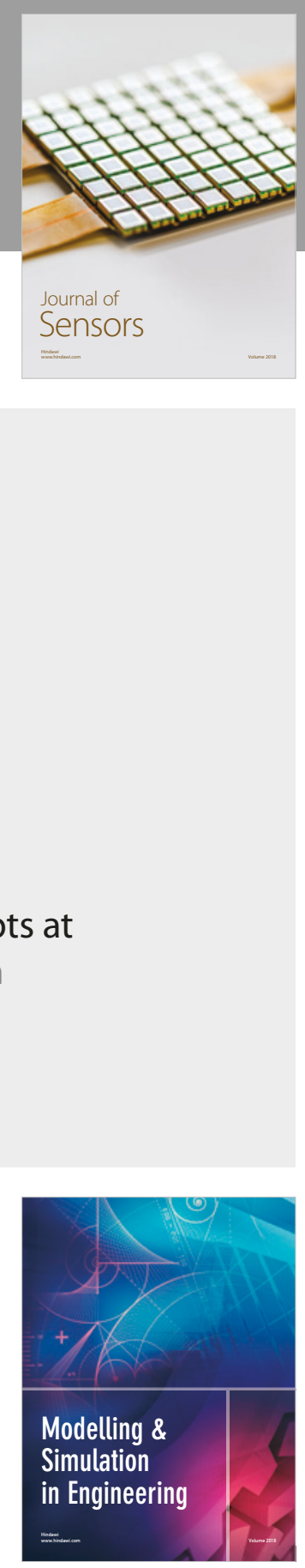

\section{Advances \\ Multimedia}
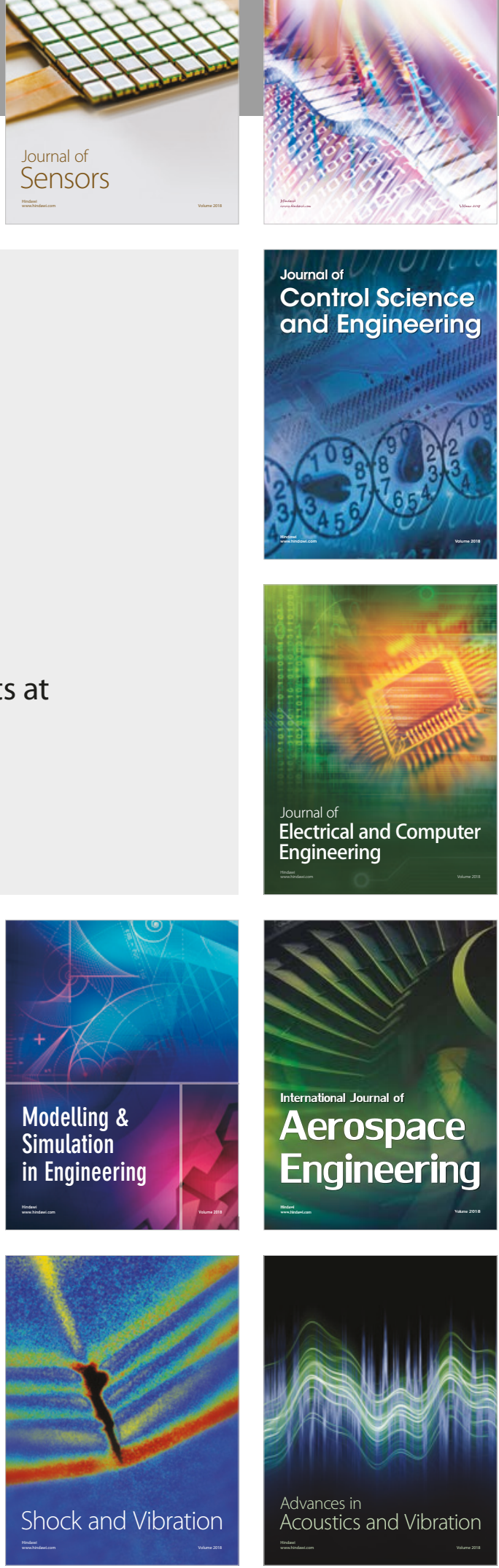